\title{
La información histórica en los archivos eclesiásticos: principales series documentales para la investigación
}

\author{
Dr. Agustín Vivas Moreno \\ Facultad de Biblioteconomía y Documentación \\ Universidad de Extremadura \\ avivas@alcazaba.unex.es \\ Dra. $M^{\text {a }}$ Guadalupe PÉREZ OrTIZ \\ Biblioteca Seminario San Antón de Badajoz \\ mgperort@alcazaba.unex.es
}

Recibido: 18/05/2011

Aceptado: 05/06/2011

\section{RESUMEN}

Por medio del presente artículo queremos dar a conocer las series documentales que tienen mayor interés para la investigación histórica en el marco de los archivos eclesiásticos. Para ello abordaremos en primer lugar, los diferentes tipos de archivos eclesiásticos existentes para ir posteriormente extrayendo de cada uno de ellos las principales y más representativas series documentales que integran su cuadro de clasificación. Más tarde, observaremos cuáles son los contenidos que pueden ser de mayor utilidad para la investigación histórica o lo que es lo mismo, mostraremos qué podemos investigar si los tomamos como punto de referencia cada uno de estos archivos.

Palabras clave: archivos eclesiásticos, investigación histórica, series documentales

\section{The historical information in the church archives: Major documentary series for research}

\begin{abstract}
The present article wants to announce the documentary series that have major interest for the historical investigation in the frame of the ecclesiastic files. For it we will approach first, the different types of ecclesiastic existing files to be extracting from each of them the principal ones and more representative documentary series that integrate his picture of classification. Later, we will observe which are the contents that can be of major usefulness for the historical investigation or that it is the same thing, will show what we can investigate if we take them as a point of reference each of them.
\end{abstract}

Key words: ecclesiastic files, documentary series, historical investigation 


\section{INTRODUCCIÓN}

Los archivos eclesiásticos son considerados como los custodios del camino seguido por la Iglesia a lo largo de los siglos, de ahí que sean tenidos en cuenta como bienes culturales de singular magnitud.

Prácticamente desde sus orígenes, la Iglesia ha intentado conservar los documentos por ella generados. En un primer momento, el objetivo no era otro que el de intemporalizar la doctrina. Han sido posteriormente los archiveros los encargados de organizarla y describirla. En otro sentido, al tratarse la Iglesia católica de una institución privada, el acceso a sus archivos es restringido, ocasionando dificultades a los investigadores. En contraposición, en estos archivos se custodia documentación valiosa y antigua dado que como es sabido la Iglesia es una de las instituciones más vetustas que han existido. Sin embargo, no podemos obviar diversas vicisitudes acaecidas a lo largo de los siglos, las cuales ocasionaron pérdidas de incalculable valor a su patrimonio. Aún a pesar de ello nuestras parroquias, catedrales, monasterios, conventos, seminarios, etc. conservan un legado documental de infinito valor histórico.

Con el desarrollo de este estudio pretendemos exponer las series documentales de mayor interés para la investigación histórica de los archivos eclesiásticos. Es decir abordar tipo por tipo los diferentes archivos eclesiásticos con los que la Iglesia católica cuenta en la actualidad e ir extrayendo aquellas series documentales que son de mayor relevancia para cada uno de ellos y cuáles son los contenidos que pueden ser útiles para la investigación histórica; es decir, qué podemos investigar atendiendo a los mismos.

\section{TIPOLOGÍAS DE ARCHIVOS ECLESIÁSTICOS}

Dado el objetivo de nuestro trabajo, se convierte en una tarea necesaria dar a conocer en primer lugar, al menos someramente, las tipologías de archivos con los que la Iglesia católica cuenta para poder posteriormente acercarnos a las principales series documentales que constituyen los cuadros de clasificación de cada uno de estos archivos y así exponer aquellos contenidos que son interesantes para la investigación histórica.

La Iglesia católica cuenta con varias clasificaciones para encuadrar sus archivos, algunas son muy similares, sin embargo hay otras con notorias diferencias que se deben, en cierto modo, al momento en el que fueron llevadas a término.

Es muy importante reseñar que en estas clasificaciones se utilizan diferentes criterios de clasificación archivísticos, hecho que da lugar a divisiones en las que se aprecian diferencias. En ningún caso se trata de clasificaciones contradictorias sino concordantes en la diversidad de criterios y además no se trata de clasificaciones excluyentes sino que admiten criterios incorporados. Todas ellas, pues, son válidas y aprovechables. A continuación procederemos muy brevemente a su exposición: 
- Código de Derecho Canónico de $1917^{1}$. Se trata del primer intento efectuado por la Iglesia para la clasificación de sus archivos. Establece: A. Diocesano, A. Secreto. A. Histórico, A. Parroquial. A. de la Iglesia catedral, las colegiatas, fundaciones y de las demás iglesias.

- Nunciatura Apostólica Española. "Los archivos eclesiásticos españoles podrán clasificarse en episcopales, catedralicios, parroquiales, monacales y de fundaciones piadosas"2.

- Diccionario de Historia Eclesiástica. Bajo la entrada "archivo" accedemos al siguiente listado: A. Vaticano, A. monacales, A. catedralicios, A. de seminarios, A. parroquiales y A. de las Cruzadas.

- Código de Derecho Canónico de $1983^{4}$. Basándose en la estructura expuesta en el anterior Código, establece los siguientes tipos de archivos: Diocesano, Secreto, Histórico, de la Iglesia catedral, las colegiatas y demás iglesias de la diócesis, de las fundaciones, de los Institutos de Vida Consagrada y de las demás instituciones.

- Diccionario del Patrimonio Cultural de la Iglesia ${ }^{5}$. En el Diccionario queda recogida la siguiente clasificación: Archivos diocesanos, Archivo Secreto, Archivos de catedrales, colegiatas y parroquias, Archivo de la Conferencia Episcopal.

- Asociación de Archiveros de la Iglesia (1997). A pesar del tiempo trascurrido desde su promulgación, a día de hoy, puede ser considerada como una de las más pertinentes clasificaciones con las que cuenta la Iglesia católica. En ella, los archivos serán clasificados atendiendo a varios criterios: antigüedad, ámbito eclesiástico y función que desempeñan.

a) Según su antigüedad: Archivos parroquiales y episcopales, Archivos monacales y de órdenes religiosas, Archivos catedralicios, del cabildo y de centros educativos del clero, Archivos de grupos y asociaciones de fieles (cofradías, hermandades) e instituciones hospitalarias y escolares.

b) Según su ámbito eclesiástico: Diocesanos, Parroquiales, Archivos de entes no sometidos al obispo diocesano y Archivos de personas jurídicas.

c) Según la función que desempeñan: Archivos corrientes, Archivos históricos y Archivos secretos diocesanos.

\footnotetext{
${ }^{1}$ Código de Derecho Canónico de 1917. Madrid: BAC, 1999.

2 "Carta circular de la Nunciatura Apostólica en España a los Reverendísimos Prelados sobre la reorganización de los archivos eclesiásticos (1929)", Hispania Sacra VI (1953), pp. 231-240.

3 Aldea Vaquero, Q.; Marín Martínez, T.; Vives Gatell, J. Diccionario de Historia Eclesiástica. Madrid: Instituto Enrique Florez, 1972, pp. 82-85.

${ }^{4}$ Código de Derecho Canónico. Madrid: Trivium, 1992.

${ }^{5}$ Iguacen Borau, D. Diccionario del patrimonio cultural de la Iglesia. Madrid: Encuentro, 1999, pp. 140-143.
} 
- Manual de Archivos Eclesiásticos ${ }^{6}$. Respecto al tema que nos compete, se incluye una amplía clasificación en la que se incluyen: Archivos parroquiales, Archivos capitulares o catedralicios, Archivos episcopales o diocesanos, Archivos monásticos, Archivos de órdenes religiosas de vida activa y Archivos de seminarios.

Veamos conjuntamente las clasificaciones expuestas:

\begin{tabular}{|c|c|c|c|c|c|c|}
\hline \multicolumn{7}{|c|}{ TIPOLOGÍAS DE ARCHIVOS ECLESIÁSTICOS } \\
\hline $\begin{array}{c}\text { C. } \\
\text { DERECHO } \\
\text { CANÓNICO } \\
\text { (1917) }\end{array}$ & $\begin{array}{c}\text { NUNCIATURA } \\
\text { (1929) }\end{array}$ & $\begin{array}{c}\text { DICC. HISTORIA } \\
\text { ECLESIÁSTICA } \\
(1972)\end{array}$ & $\begin{array}{c}\text { C. } \\
\text { DERECHO } \\
\text { CANÓNICO } \\
\text { (1983) }\end{array}$ & $\begin{array}{c}\text { DICC. } \\
\text { PATRIMONIO } \\
\text { CULTURAL } \\
\text { (1991) }\end{array}$ & $\begin{array}{c}\text { ASOCIACIÓN } \\
\text { ARCHIVEROS } \\
\text { DE LA IGLESIA } \\
\text { (1997) }\end{array}$ & $\begin{array}{c}\text { MANUAL } \\
\text { DE } \\
\text { ARCHIVOS } \\
\text { (1999) }\end{array}$ \\
\hline Diocesano & Diocesano & & Diocesano & Diocesano & Diocesano & Diocesano \\
\hline Catedral & Catedral & Catedral & Catedral & Catedral & Catedral & Catedral \\
\hline Parroquial & Parroquial & Parroquial & Parroquial & Parroquial & Parroquial & Parroquial \\
\hline \multicolumn{7}{|l|}{ Histórico } \\
\hline Secreto & & & Secreto & Secreto & & \\
\hline Colegiata & & & Colegiata & Colegiata & & \\
\hline \multirow[t]{9}{*}{ Fundaciones } & Fundaciones & & & & & \\
\hline & Monacal & Monacal & & & Monacal & Monacal \\
\hline & & Vaticano & & & & \\
\hline & & Seminario & & & & Seminario \\
\hline & & Santa Cruzada & & & & \\
\hline & & & & C. Episcopal & & \\
\hline & & & & & Hospitales & \\
\hline & & & & & Asoc. fieles & \\
\hline & & & & & & Órd. activa \\
\hline
\end{tabular}

1. Tipologías de archivos eclesiásticos

Una vez expuestos los principales tipos de archivos eclesiásticos, según las clasificaciones con las que la Iglesia católica cuenta, hemos optado por una clasifica153.

${ }^{6}$ Rubio Merino, P. Archivística Eclesiástica: Nociones básicas. Sevilla: Guadalquivir, 1999, pp. 53- 
ción que incluirá los siguientes tipos ${ }^{7}$ : parroquiales, catedralicios, diocesanos, conventuales-monacales, de beneficencia, de órdenes de vida activa y de seminarios.

\section{LOS ARCHIVOS ECLESIÁSTICOS Y LA INVESTIGACIÓN HISTÓRICA: CONTENIDOS}

\section{Series para la investigación histórica en los archivos parroquiales.}

El archivo parroquial es la unidad básica del sistema de archivos de la Iglesia católica. Su misión, en líneas generales, consiste en conservar los documentos que las parroquias producen o reciben en el desarrollo de su ministerio, así como los relacionados con la administración de sus bienes. Como todos sabemos fue el Concilio de Trento el que instauró la obligación de archivar la documentación eclesiástica (parroquial y diocesana) en archivos. Los párrocos y vicarios fueron los encargados de estas tareas. En España, de forma concreta, fue el rey Felipe II el que por decreto de 12 de julio de 1564 impuso estas cuestiones, que fueron aceptadas sin mayor complicación dado que muchos archivos parroquiales ya habían comenzado con estas prácticas tiempo atrás ${ }^{8}$.

En la actualidad, el Código de Derecho Canónico, en su canon 535.1, se refiere al registro de los libros sacramentales que otorga directamente al párroco, señalando que debe hacer anotaciones con exactitud y que además de la confección de los libros sacramentales debe custodiar documentación emitida por el obispo y todo lo que día a día genere la parroquia. Por su parte, el canon 491.1 habla de la conveniencia de la creación de un inventario y en otros cánones se desarrollan cuestiones relativas al acceso al archivo y a su documentación, así como la formación que requieren los sacerdotes para poder hacer frente diligentemente a estas tareas (c. 256). En líneas generales, el cuadro de clasificación de un archivo parroquial da cabida a una estructura básica, que es la que representa la parroquia en sí misma, pero a la vez compleja como fruto de sus múltiples relaciones, competencias y actividades. A nuestro entender debería estar dividido en seis secciones fundamentales, aunque pudiera darse el caso de que aparecieran otras o no existieran todas las que exponemos: administración, fondos musicales, gobierno, instituciones parroquiales, organismos supra parroquiales y sacramentales. Dentro del mismo, y por la importancia que representan de cara a futuras investigaciones históricas que no tengan que ver con cuestiones puramente administrativas o gubernativas, que se repiten en cada tipo de archivo, hemos señalado como relevantes las siguientes series documentales:

\footnotetext{
${ }^{7}$ La utilización de esta subdivisión y no de otra, está basada tal y como ha quedado constatado en que es una de las más ampliamente reconocidas en el panorama archivístico eclesiástico actual.

${ }^{8}$ AZCONA SAN MARTÍN, F. "Los archivos parroquiales desde el Concilio de Trento hasta el siglo XX”, Fuentes Estadísticas XXV (1997).
} 
1. Capellanías y obras pías ${ }^{9}$. Esta serie documental se sitúa en la sección instituciones parroquiales, concretamente dentro de la subsección fundaciones que se constituye además de la serie documental aniversarios. En líneas generales las capellanías son fundaciones de origen medieval que tuvieron gran auge en España, Portugal y sus colonias en América durante los siglos XVI, XVII y XVIII. Fundamentalmente eran obras pías instauradas en la Iglesia Católica, mediante las cuales el fundador, generalmente una persona acaudalada, dejaba en su testamento una cantidad de dinero que se ponía en renta, para que con las ganancias se pagara la realización de un número de misas por la salvación de su alma y de su familia.

Son varios los contenidos que pueden ser de utilidad para la investigación histórica tomando este punto de referencia:

Por un lado, la llamada economía espiritual. Desde los siglos XVI al XVIII se vino dando lo que algunos historiadores han dado en llamar economía espiritual en virtud de que la mayor parte de las manifestaciones piadosas tenían un sustrato económico y planteaban que las actividades a favor del alma constituían una inversión para obtener una posición mejor en el más allá, incluso algunas veces en el mundo presente. Este contenido nos permitirá acceder a aspectos concretos de la religiosidad de la época, así como entrever lo que era considerado como fervor religioso y poder establecer así marcos comparativos con otras épocas de mayor laicismo. Incluso nos permitirá abordar cuestiones intrínsecamente relacionadas a las anteriores, como son las indulgencias, tema que ha despertado gran interés a lo largo de todos los tiempos entre los investigadores de estos ámbitos.

Por otro lado, accedemos a contenidos históricos. Los contenidos históricos son múltiples si tenemos en cuenta que las actas fundacionales de capellanías y obras pías conservadas en las parroquias son muchas. En base a ello, podremos acceder a datos puramente nominativos, es decir, qué familias formaron parte de estos procesos y de este modo acceder a linajes completos que favorecieron económicamente a la Iglesia católica con estas prácticas piadosas y también a datos económicos y patrimoniales dado que analizando dichos expedientes podemos extraer relaciones complejas de bienes que nos permitirán estudiar por una parte, cuestiones puramente contables, a nuestro juicio las menos interesantes, pero además cuestiones artísticas dado que muchas de estas familias entregaban a las familias piezas de arte que han constituido los riquísimos fondos artísticos con los que algunas entidades cuentan y que han sido objeto de estudio e investigación a lo largo de los siglos.

\footnotetext{
${ }^{9}$ Esta serie documental no es exclusiva del cuadro de clasificación de los archivos parroquiales dado que puede aparecer en catedralicios, diocesanos y monásticos-conventuales, pero si es cierto, que en los parroquiales adquiere una gran importancia y representan contenidos de gran valor histórico.
} 
2. En la sección fondos musicales se sitúan dos series documentales de suma relevancia para los archivos parroquiales: libros de música y partituras dado que representan unos contenidos de gran importancia para la historia de la cultura, de la música y en general, del arte. Aparecen también esta serie documental en los archivos catedralicios o capitulares, conventuales y monásticos. En algunos casos estas obras musicales son piezas únicas de incalculable valor, especialmente cuando nos referimos a partituras compuestas para ser impartidas en una celebración religiosa concreta dentro de la parroquia, es decir, los llamados encargos musicales que llegaron a ser muy frecuentes, especialmente en los días en los que se celebraban las fiestas patronales de una localidad determinada o en la celebración de alguna novena en honor a santos destacados en dichas poblaciones.

3. Reliquias: Se trata de una serie documental que se sitúa dentro de la sección organismos supra parroquiales, concretamente en la subsección denominada documentación de la Curia Romana. Junto a ella aparecen otras dos series documentales breves-bulas y encíclicas-cartas apostólicas. Todas aquellas parroquias que dispongan de alguna reliquia custodiarán una importantísima documentación emitida desde Roma que da fe del proceso de validación de la misma y que se acompaña en muchos casos de datos históricos sobre la reliquia en cuestión. Estos contenidos son de sumo interés para la investigación histórica, espiritual y patrimonial de los pueblos donde se ubican, es decir, son parte de su historia artístico-cultural dado que la reliquia, en la gran mayoría de casos, suele ser una pieza de valor artístico que nos permite el estudio de cuestiones variadas sobre el arte cristiano y además el sustento de muchas investigaciones sobre religiosidad popular puesto que siempre van envueltas de una halo de misticismo y religiosidad que muchas veces es difícil de diferenciar.

4. Breves y Bulas. Como en el caso anterior se sitúa esta serie dentro de la sección organismos supra parroquiales, concretamente en la subsección denominada documentación de la Curia Romana. Junto a ella aparecen otras dos series documentales reliquias y encíclicas-cartas apostólicas. Se trata de una documentación significativa dado que pone en relación directa a los principales órganos de la Iglesia católica (Curia Romana) con las parroquias, cuestión que no era muy usual puesto que la comunicación solía realizarse por medio de los obispados que actuaban como intermediarios canalizando y distribuyendo la información. Por ello, en las parroquias que existe la citada documentación adquiere un valor importante que deberá quedar plasmado en su cuadro de clasificación dado que se tratará de disposiciones, recomendaciones, informaciones, documentos pontificios relativos a materia de fe o de interés general, concesión de gracias o privilegios o asuntos judiciales o administrativos, etc para ser aplicados de forma exclusiva en la citada entidad debido a situaciones especiales o particulares.

5. Comunicaciones con la Santa Cruzada. Esta serie documental se sitúa dentro de la sección organismos supra parroquiales, concretamente en la sub- 
sección denominada de la Santa Cruzada que queda constituida exclusivamente por esta serie. Se trata de unos contenidos que merecen la pena ser resaltados en este estudio por su singularidad dado que la Santa Cruzada fue un organismo que se creó dentro de la Iglesia católica para gestionar lo relativo a estas materias, es decir, en líneas generales restablecer el control cristiano de Tierra Santa. Es por tanto una documentación de sumo interés para el estudio de la historia de la Iglesia, especialmente de los siglos XI al XIII etapa en la que se desarrollaron.

6. Partidas sacramentales: esta serie se sitúa dentro de la sección sacramentales y aparece dividida en tantas subsecciones como tipos de partidas existen en el ámbito de la Iglesia católica: bautismos, confirmaciones, defunciones y matrimonios. Es sin lugar a duda, una sección clave dentro del cuadro de clasificación de los archivos parroquiales dado que llevar un registro de la administración de estos sacramentos es una de las tareas primordiales de las parroquias. Las partidas sacramentales son una fuente de datos históricos de un valor incalculable. Desde el siglo XVI las parroquias tienen la obligación de llevar al día un registro, a modo de libro, para cada uno de estos sacramentos donde queden anotados todas y cada una de estas celebraciones. Los datos que aportan estas partidas, especialmente las de bautismo, están permitiendo a los investigadores configurar árboles genealógicos de varias generaciones que no hubieran podido ver nunca la luz sin los contenidos que aportan los archivos parroquiales. Además, estos datos son de gran interés para los estudios de tipo demográfico ya que esta documentación es la única que atestigua la vida o la muerte (partidas de bautismo y de defunción) de una persona cuando la documentación civil no existe. Aunque en la actualidad estas cuestiones pudieran ser consideradas como meramente anecdóticas, en otras épocas no eran inusuales y muchas personas debían recurrir a la Iglesia católica para obtener estos certificados que les eran indispensables para variados trámites ${ }^{10}$.

7. Además podríamos citar el interés de esta documentación para el estudio de la beneficencia y la sanidad principalmente de los siglos XVI-XVIII dado que estas instituciones, como órgano base de la Iglesia católica, fueron también centros que canalizaron la ayuda que la Iglesia ofrecía a los necesitados. Existen variados estudios sobre estas cuestiones que no permiten observar como fue la Iglesia la que durante siglos se encargó de combatir la mendicidad y las epidemias que afloraban en sus ciudades.

${ }^{10}$ En la actualidad se está trabajando incesantemente en cuestiones relativas a la protección de los datos que están partidas reflejan. Sin embargo, esperamos que aquellos datos históricos que muchas de ellas contienen y que ha nadie pueden ya afectar dado lo dilatado su fecha de emisión, no se vean afectados por estas normativas y puedan seguir siendo sustento de valiosos estudios e investigaciones como lo han hecho hasta el momento sin ocasionar daño alguno a la sociedad. 
En resumen:

\begin{tabular}{|l|l|l|}
\hline \multicolumn{3}{|c|}{ ARCHIVO PARROQUIAL } \\
\hline \multicolumn{1}{|c|}{ Series documentales } & \multicolumn{1}{c|}{ Contenidos } & \multicolumn{1}{c|}{ Otros archivos } \\
\hline Capellanías y obras pías & $\begin{array}{l}\text { Economía espiritual, } \\
\text { relación de bienes, } \\
\text { religiosidad, arte, etc }\end{array}$ & $\begin{array}{l}\text { Diocesanos, monásticos y } \\
\text { conventuales }\end{array}$ \\
\hline Reliquias & Religiosidad popular, arte & $\begin{array}{l}\text { Catedralicios, monásticos } \\
\text { y conventuales }\end{array}$ \\
\hline Breves y Bulas & Curia Romana & Diocesanos \\
\hline $\begin{array}{l}\text { Comunicaciones con la } \\
\text { Santa Cruzada }\end{array}$ & Cruzadas & Diocesanos \\
\hline Partidas sacramentales & Datos & Diocesanos (en depósito) \\
\hline Beneficencia & $\begin{array}{l}\text { Mendicidad, epidemias, } \\
\text { niños }\end{array}$ & $\begin{array}{l}\text { Beneficencia, órdenes de } \\
\text { vida activa }\end{array}$ \\
\hline
\end{tabular}

\section{Series para la investigación histórica en los archivos diocesanos}

En líneas generales, los archivos diocesanos o episcopales son aquellos que custodian la documentación generada por el obispo y su curia en el desarrollo de las actividades que les han sido asignadas.

Su datación se sitúa hacia el siglo XVI, muy estrechamente ligada a las cláusulas emanadas del Concilio de Trento (1545-1563), en las que se dispone la observancia de residencia obispal obligatoria. Hasta la fecha, no residían en las diócesis encomendadas sino en otras donde obtenían mayores beneficios. Debido a ello, hasta dicho momento, la documentación diocesana era ubicada junto al fondo catedralicio como consecuencia directa de que el obispo formaba parte del cabildo y de la inexistencia de archivos diocesanos. Este hecho originó grandes perdidas documentales que jamás han podido ser subsanadas. En los años que siguen al Concilio de Trento las pautas tridentinas fueron aplicadas con cautela y los archivos episcopales fueron afianzándose en el tiempo. Debemos esperar hasta el primer cuarto del siglo XVIII para hacer mención a un hecho de gran repercusión en la archivística episcopal, la Constitución Máxima Vigilantia que fue aprobada el 14 de junio del 1724 por el Papa Benedicto XIII. En líneas generales, se formuló con el propósito de organizar los archivos de la Iglesia a escala universal y sus disposiciones se encuentran dirigidas especialmente a los archivos diocesanos. El capítulo VI de la citada Constitución recoge las principales disposiciones en materia archivística: creación de inventarios y catálogos, consolidación del carácter privado de la documentación diocesana, constitución del archivo secreto y formación específica de 
los archiveros diocesanos ${ }^{11}$. En la actualidad, los archiveros eclesiásticos vienen orientando su esfuerzo en la consecución de un Sistema Archivístico Diocesano. Es importante señalar que el archivo histórico diocesano no fue introducido hasta abril de 1980, aún así, existen varias diócesis en España que están alcanzado dichos propósitos. A pesar de su tardío nacimiento y de los avatares a los que tuvieron que enfrentarse hasta su consolidación, los archivos episcopales han destacado por su volumen y riqueza documental como unos de los más relevantes dentro del panorama archivístico de la Iglesia católica. Este hecho ha dado lugar a una interesantísima producción bibliográfica que permite el conocimiento en profundidad de este tipo de entidades. El cuadro de clasificación de los archivos diocesanos representa la complejidad de esta institución y las múltiples relaciones que se establecen dentro de la misma. De este modo suele quedar constituido en tres grandes secciones: administración, gobierno y justicia que se subdividen en multitud de subsecciones y series documentales.

Como en el caso de los parroquiales, en los archivos diocesanos los contenidos sobre capellanías y obras pías son abundantes. Éstos serán un foco importante de datos para las investigaciones y serán complemento vital para el estudio de lo que estas fundaciones pías significaron en el marco de la Iglesia católica, uniéndose a los contenidos extraídos en los archivos parroquiales. Sin dejar al margen esta serie pero evitando repeticiones, nos centraremos en otras series documentales más específicas de su cuadro de clasificación:

1. Los diezmos y primicias. Esta primera serie documental se ubica dentro de la sección administración, concretamente dentro de la primera de las subseciones que la constituyen, la denominada colecturía. Se integra únicamente de dos series documentales que son las que vamos a ver a continuación. La documentación sobre diezmos refleja el pago, generalmente de una décima parte de la cosecha, que desde antaño se vino haciendo a la Iglesia. Por su parte, la documentación generada por las prestaciones de frutos o ganados que, además de los diezmos, debían ser cedidas a la Iglesia era lo que se conocía como primicias. El obispado como máximo órgano eclesiástico en la diócesis custodia, en sus archivos diocesanos, la documentación que acredita el pago de estos tributos. Hemos considerado estos contenidos destacables dentro del cuadro de clasificación de los archivos diocesanos porque reflejan una abundantísima documentación que nos permite estudiar un proceso históricoeconómico que fue sumamente relevante. El estudio de estos contenidos nos ayudará a clarificar la significación de un fenómeno que muchos, desde la perspectiva actual, ven como un mero abuso de poder y engrandecimiento por parte de la Iglesia pero que el momento en el que se desarrolló era una cuestión que iba más allá de estas predisposiciones.

2. Censos. La serie documental censos es de gran significación dentro del cuadro de clasificación de los archivos diocesanos, muy especialmente por su

${ }^{11}$ RUBIO MERINO, P. Archivística Eclesiástica: Nociones básicas. Sevilla: Guadalquivir, 1999, pp. 107-108. 
singularidad. Se sitúa junto con la serie cuentas, como en el caso anterior, dentro de la sección Administración, concretamente en la subsección mitra. En líneas generales, podemos decir que dentro de la economía agraria de España las tierras estaban gravadas por una serie de rentas que se llamaban censos. Éstos, pagados en especie, sirvieron de sustento tanto a la monarquía como a la Iglesia durante un periodo importante de tiempo. La documentación sobre censos es realmente importante y voluminosa en los archivos episcopales dado que la Iglesia, a lo largo de los tiempos, fue beneficiada por muchos de ellos. Como se puede observar, que esta documentación se conserve en los archivos diocesanos los convierte en garantes de una seguridad económica. El estudio de dichos contenidos nos permitirá, como en el caso de los diezmos, comprender un proceso histórico-económico que en la actualidad carece de la repercusión que tuvo en épocas pasadas y nos acercará a una parte de la historia que se desarrolla casi de forma singular en esta documentación.

3. Padrones parroquiales. Esta serie documental se sitúa dentro de la sección administración constituyendo una parte importante del cuadro de clasificación de los archivos episcopales donde nos ubicamos en este momento. Los padrones parroquiales pueden ser comparados con las listas censales en la vertiente civil dado que recogen datos de las personas que pertenecen a una determinada parroquia, así como a su participación de los sacramentos. El interés de esta serie documental no viene intrínsecamente relacionado a su parte más eclesial, es decir, a la administración de los sacramentos, que puede ser estudiado más ampliamente analizando otras series documentales, sino más bien a su parte sociológica y demográfica dado que nos permitirá observar cómo se distribuye la población a nivel de iglesia.

4. Anulaciones y dispensas matrimoniales. Se localiza esta sección dentro de la sección justicia, concretamente en la subsección matrimonios. A su vez, ésta se constituye únicamente por las dos citadas series documentales. Se trata de una documentación única, es decir, ningún otro archivo eclesiástico de los que van a ser expuestos en este trabajo recogen documentación sobre estas cuestiones. Por ello, estos contenidos adquieren un valor realmente importante, aunque su valía no es como en otros casos de marcado carácter histórico dado que son casos particulares de personas que han participado en alguno de estos procesos y debemos siempre salvaguardar la intimidad de las personas que se vieran afectadas, respetando los años que la Archivística en general y de forma particular la eclesiástica establece. Es importante traer a colación esta serie documental no tanto en cuanto a los contenidos históricos que nos aporta, como ya hemos dicho, pero si dado que al tratarse de una documentación única las personas que han participado en alguno de estos procesos sólo pueden encontrar en este archivo el documento que atestigüe la validez del mismo. Se convierte así en una documentación de marcado carácter probatorio.

5. Bienes de cofradías: inventarios. Situada dentro de la sección gobierno, constituye junto con las series acuerdos de cofradías, elecciones de cofradías y nombramientos una de las más importantes subsecciones hermandades y 
cofradías, en la que se podrá acceder, como es lógico, a cuestiones relativas a estas entidades. Al margen de cuestiones puramente económicas, como las que hemos traído a colación en líneas anteriores, los archivos diocesanos destacan también porque son una fuente documental para el estudio del arte. No se trata de un arte propio, como ocurre en parroquias, catedrales, monasterios y conventos, le es del todo ajeno, es decir, son meros depositarios del mismo. El archivo episcopal custodia documentación artística de otras entidades, especialmente cofradías y hermandades, al tratarse de entidades menores. Las cofradías y hermandades tenían la obligación de presentar al obispado la documentación sobre sus bienes patrimoniales y artísticos, además no debemos olvidar que estas carecían de archivos propios. Dejando al margen sus cuentas destacaremos la documentación sobre su patrimonio artístico que para algunas de estas instituciones es de incalculable valor: tallas, joyas, mantos, bordados, candelabros, piezas de orfebrería etc constituyen sus bienes. El archivo diocesano no recoge la pieza en si, que se atesora generalmente en las parroquias o en algunos casos en dependencias propias de la hermandad, pero si da fe documental de todas y cada unas de estas piezas. Por ello, cualquier estudio sobre las mismas requerirá de una fundamentación documental que se sitúa en los archivos episcopales.

En resumen:

\begin{tabular}{|l|l|l|}
\hline \multicolumn{3}{|c|}{ ARCHIVO DIOCESANO } \\
\hline \multicolumn{1}{|c|}{ Series documentales } & \multicolumn{1}{|c|}{ Contenidos } & \multicolumn{1}{c|}{ Otros archivos } \\
\hline Capellanías y obras pías & $\begin{array}{l}\text { Economía espiritual, } \\
\text { relación de bienes, } \\
\text { religiosidad, arte, etc }\end{array}$ & $\begin{array}{l}\text { Diocesanos, monásticos y } \\
\text { conventuales, parroquiales }\end{array}$ \\
\hline Diezmos y primicias & $\begin{array}{l}\text { Económicos, beneficios, } \\
\text { religiosidad }\end{array}$ & Catedralicios \\
\hline Censos & Procesos económicos & $\begin{array}{l}\text { Parroquiales, catedralicios } \\
\text { y monásticos }\end{array}$ \\
\hline Padrones parroquiales & Datos & ----- \\
\hline Anulaciones y dispensas & $\begin{array}{l}\text { Documentación } \\
\text { acreditativa del proceso }\end{array}$ & ----- \\
\hline Bienes: cofradías & Arte, religiosidad popular & Parroquiales \\
\hline
\end{tabular}

\section{Series para la investigación histórica en los archivos capitulares}

Los archivos capitulares o catedralicios custodian la documentación producida o recibida por los cabildos catedralicios en el desarrollo de sus competencias litúrgicas y de culto. El origen de los archivos capitulares hay que buscarlo en los clérigos que, 
desde el siglo IV, hacían vida colectiva, sometidos a una regla y con dedicación plena al culto público, la liturgia y las necesidades de la catedral. El IV Concilio de Toledo habla de ellos por primera vez. Más adelante, en la Edad Media, surgen corrientes renovadoras que encuentran seguidores en determinados grupos de clérigos, que deseosos de acabar con los ambientes viciados terminan uniéndose para comenzar una vida más ajustada a las normas. Pronto, este peculiar sistema de vida irá tomando fuerza y los cabildos se convertirán en instituciones necesarias dentro de la Iglesia. Durante el siglo $\mathrm{X}$, los cabildos viven momentos de flaqueza motivados por el cansancio de sus miembros y la dilapidación de sus bienes a mano de algunos obispos. Para solventar este problema se decidió dividir en dos la masa común, creándose una mesa episcopal y otra capitular. Fue San Damián quien se propuso restaurar la vida en común creando el Instituto de Canónigos Regulares cuyos miembros actuaban bajo la Regla de San Agustín. Transcurrido el tiempo, el cabildo, como institución, termina consolidándose y adquiriendo gran prestigio. De este modo, se convierte en el órgano de gobierno del obispo ${ }^{12}$.

Muchos son los contenidos históricos que pueden ser extraídos de sus complejos cuadros de clasificación, que no son más que el reflejo de estructuras que se dilatan en el tiempo desde los comienzos de la Edad Media hasta nuestros días. De todos ellos hemos destacado los siguientes:

1. Dentro de la sección capilla musical vamos a hacer alusión a tres de sus series documentales: canto llano-polifonía (pertenecen a la subsección de libros cantorales), expedientes de músicos (subsección documentación biográfica) y partituras propias (subsección partituras) dado que representan unos contenidos de gran relevancia para la historia de la cultura, de la música y en general, del arte. Aparecen también en los archivos parroquiales conventualesmonásticos pero su significación, volumen y relevancia es notoriamente menor, exceptuando ejemplos concretos en ciertos monasterios del norte de España, que conservan piezas musicales de relevancia. En algunos casos estas obras musicales son piezas únicas de incalculable valor, especialmente cuando nos referimos a partituras compuestas en las catedrales para ser impartidas en una celebración religiosa concreta dentro de la misma catedral, es decir, los llamados encargos musicales que sólo aparecen en ese archivo capitular (partituras propias). Lo mismo sucede con la documentación que existe sobre músicos y compositores, algunos contenidos biográficos son inéditos y su difusión solamente será posible si accedemos a estos magníficos archivos. Algunas biografías de grandes compositores, nacionales e internacionales, han tomado forma en estos archivos eclesiásticos.

2. Junto a esta documentación debemos hacer mención a otra serie documental denominada nóminas de artistas dado que nos da a conocer contenidos de sumo valor para historia del arte. Situada en la sección fábrica, constituye junto con las series documentales ingresos ocasionales y nóminas de obreros, una particular subsección de este cuadro de clasificación llamada adventicios.

${ }^{12}$ RUBIO MERINO, P. Archivística Eclesiástica... Op. Cit., pp. 84-86. 
Resaltamos esta serie documental porque aunque se trata de una documentación de carácter contable puede aportar datos interesantes que van más allá de lo puramente económico. En las catedrales llegaron a concentrarse un importante número de pintores, escultores y arquitectos, vidrieros, etc que hicieron de estos templos verdaderas joyas del arte. La documentación de cada uno de sus trabajos, planos, bocetos, etc se custodia en los archivos capitulares. Su estudio nos mostrará datos de gran valor para la historia de nuestro patrimonio artístico dado que para el estudio de la arquitectura eclesiástica se ha recurrido como principal fuente documental a los expedientes custodiados en los archivos capitulares. Éstos han sido la prueba de los procesos arquitectónicos llevados a término permitiendo, a alumnos de universidades y escuelas y a investigadores de todo tipo, comprender formas de construcción utilizadas hace siglos. Además esta documentación aporta datos económicos sobre el coste de los trabajos realizados y las formas de pago. Por otro lado, es conveniente destacar los contenidos que tienen que ver con procesos de restauración. Las catedrales custodian también en sus archivos expedientes sobre restauraciones de pinturas, tapices, esculturas que albergan datos singulares para la historia del arte y que son focos de contenidos de gran interés para los investigadores de estas materias. Gracias a esta documentación se han conservado técnicas de restauración que se aplican en la actualidad y han permitido a los historiadores conocer procesos de que hubieran desaparecido en el tiempo de no haber existido documentación que lo atestiguase.

3. Además debemos resaltar las colecciones de sellos y monedas de las que algunos archivos capitulares son custodios. Estas series documentales son muy heterogéneas y no aparecen en todos los cuadros de clasificación de archivos capitulares. Cuando lo hacen forman parte de una sección independiente denominada varios que se integra de diferentes series documentales dependiendo de cada caso. Los sellos y monedas son entendidos como un testimonio más de la historia de nuestras civilizaciones, algunas catedrales poseen un rico patrimonio numismático, que permiten en el estudio de variadas monedas y medallas, algunas de ellas debidamente documentadas. De especial interés son las que se custodian sobre los santos patronos de las ciudades donde se erigen las catedrales. Los amantes de la filatelia encontrarán en estos archivos interesantes focos de estudio.

4. Cartularios. Cartularios es otra de las series documentales a destacar dentro del cuadro de clasificación de los archivos capitulares. Se sitúa dentro de la sección mesa capitular/mayordomía, concretamente en la subsección bienes del cabildo que queda constituida junto con la serie expuesta por otras dos series documentales denominadas heredades y protocolos. Esta serie denominada en otros archivos como libro de becerro o de tumbos hace referencia al lugar donde catedrales, iglesias y monasterios anotaban a mano los privilegios y demás escrituras que les habían sido concedidos. La catedral solía ser receptora de muchos privilegios, más importantes y voluminosos que los que se otorgaban a iglesias y monasterios. Por ello, los cartularios catedralicios son 
fuentes de datos históricos de singular importancia que nos permitirán conocer qué privilegios fueron concedidos por los reyes, nobles y papas, así como qué benefactores tuvo una catedral en momentos concretos de su historia. En muchos casos se trata de una documentación que únicamente se conserva en estos archivos y que es la única prueba de dichos beneficios.

En resumen:

\begin{tabular}{|l|l|l|}
\hline \multicolumn{3}{|c|}{ ARCHIVO CAPITULAR } \\
\hline \multicolumn{1}{|c|}{ Series documentales } & \multicolumn{1}{|c|}{ Contenidos } & \multicolumn{1}{c|}{ Otros archivos } \\
\hline Capellanías y obras pías & $\begin{array}{l}\text { Economía espiritual, } \\
\text { relación de bienes, } \\
\text { religiosidad, arte, etc }\end{array}$ & $\begin{array}{l}\text { Diocesanos, monásticos y } \\
\text { conventuales }\end{array}$ \\
\hline $\begin{array}{l}\text { Música: cantollano- } \\
\text { polifonía, expedientes } \\
\text { músicos, partituras }\end{array}$ & $\begin{array}{l}\text { Partituras, biografías, } \\
\text { libros de canto, etc }\end{array}$ & Parroquiales \\
\hline Nóminas de artistas & $\begin{array}{l}\text { Biografías, doc. sobre } \\
\text { piezas }\end{array}$ & Parroquiales \\
\hline Sellos y monedas & $\begin{array}{l}\text { Documentación } \\
\text { acreditativa }\end{array}$ & ---- \\
\hline Cartularios & $\begin{array}{l}\text { Datos históricos, } \\
\text { privilegios, beneficios }\end{array}$ & $\begin{array}{l}\text { Monásticos y } \\
\text { conventuales }\end{array}$ \\
\hline
\end{tabular}

\section{Series para la investigación histórica en los archivos monásticos-conventuales}

Los archivos monásticos y conventuales son los grandes depósitos de la cultura medieval y en contraposición son inmensamente desconocidos para la historia, aunque recogen contenidos de extremo valor histórico y de una singularidad tal, que los hace ser preservados por la Iglesia católica con su mayor esmero. Desde los primeros siglos, el sentir cristiano ha buscado la perfección ascética apartándose del mundo. Muchos fueron los que huyendo de las persecuciones de los emperadores romanos buscaron refugio en la soledad de los desiertos. Son los llamados eremitas, que vivían entregados a la oración y a la penitencia. Pronto aumentaron en número y, en cierto modo, se vieron obligados a ponerse bajo la jurisdicción de un maestro que les guiara. De este modo, aparecen los cenobios. El monacato siguió floreciendo con la aparición de nuevas órdenes (Cister y Cluny). Pronto surgieron las órdenes mendicantes, que respondían a la necesidad de acomodarse a la sociedad en la que se desarrollaban. Los mendicantes, fieles a la vida en comunidad, prescinden del aislamiento de otras épocas.

Las órdenes religiosas, tanto monásticas como mendicantes, son, y han sido a lo largo de los siglos, fuente de una inmensa producción documental. Su cuadro de 
clasificación se presenta dividió en tres grandes secciones: gobierno, justicia y administración que corresponden a las tres principales funciones de estas entidades. Debemos resaltar nuevamente en estos archivos contenidos que nos proporcionan series documentales ya analizadas para otros archivos eclesiásticos. Por una parte las capellanías y obras pías, aunque su volumen es menor que al referirnos a las parroquias y catedrales, en los archivos monásticos-conventuales encontramos abundante documentación al respecto que nos permite trabajar sobre las cuestiones expuestas. Como en el caso de los archivos catedralicios destacaremos los libros de becerro, donde a mano los religiosos anotaban los privilegios que les habían sido concedidos por papas, reyes, nobles, etc. Son de especial relevancia los documentos que se conservan en algunos monasterios del norte de España permitiéndonos analizar la empatía que desde la corona y la nobleza se depositaba sobre ciertas comunidades.

De forma exclusiva para los archivos monásticos-conventuales destacaremos las siguientes series documentales:

1. Escrituras de patronazgo. Se sitúa dentro de la sección administración, dentro de una importante subsección denominada expedientes y escrituras de adquisiciones de bienes. Dicha subsección se integra de varias series documentes que son: clausulas testamentarias, compras, donaciones, escrituras de patronazgo, escrituras de fundaciones, imposiciones a censos, permutas y testamento. La distribución de la misma nos permite hacernos una idea de la importancia que posee dentro de los archivos monástico-conventuales que abordamos en este momento. Las escrituras de patronazgo nos informan sobre la protección que algunos señores, nobles y reyes ofrecían a las entidades monásticas y conventuales como prueba de su buen hacer cristiano. Esta situación que favoreció enormemente a algunos monasterios, sobretodo en la Edad Media, es interpretada por algunos historiadores como parte de lo que ya hemos llamado economía espiritual, es decir, se ofrecía protección y privilegios a los monasterios a cambio de rezos y celebraciones de misas que fueran aplicadas para la salvación de sus almas. Los contenidos a los que podemos acceder analizando esta documentación son abundantes dado que en líneas generales podremos conocer toda una cultura que se desarrolló especialmente en el medievo, y que consistió en una especia de trueque entre protección y favor religioso (humano-divino). Además, sabremos de primera mano qué monasterios y conventos, en menor medida, fueron los más beneficiados, cómo se les favoreció y qué familias nobiliarias y reyes participaron en estos procesos convirtiéndose en patrones, es decir, datos que nos permitirán desarrollar interesantes trabajos de carácter histórico.

2. Noviciado. Se trata de una serie documental específica de este tipo de archivos que se encuadra como una de las siete subsecciones que constituye la sección gobierno. Los contenidos a los que accedemos tras el análisis de esta abundantísima documentación son muy heterogéneos y nos permiten conocer de primera mano una estructura ajena a la sociedad civil. Para muchos historiadores, especialmente los que destacan en el campo biográfico, son de especial relevancia los expedientes de aquellos novicios/as quienes años después 
llegaron a ser personas destacadas en el panorama eclesiástico: obispos, cardenales, papas, etc, incluso pudieron llegar a alcanzar la beatificación o canonización de la iglesia católica, dado que esta documentación recoge de primera mano todo tipo de datos de su época inicial y formativa, que se dilataba durante un largo número de años. Es por tanto una documentación de obligada consulta para aquellos que quieran escribir hagiografías o vidas de religiosos dado que en esta documentación accederán a contenidos que no podrán localizar en ninguna otra documentación.

3. Debemos destacar también la serie documental relativa a objetos sagrados: arte, dado que como ocurre al estudiar otras entidades (parroquias y catedrales) el volumen de objetos artísticos de valor es en algunos de los monasterios españoles realmente significativo. La documentación que se conserva en estos archivos permite estudiar las piezas artísticas (cálices, crucifijos, joyas, pinturas) y documentarlas hecho de gran significación para los historiadores del arte que ven en las fechas de datación algunos de sus mayores impedimentos para la identificación de las piezas. Algunos de estos monasterios y conventos conservan también reliquias de valor. Sus archivos serán los custodios de la documentación que atestigua la veracidad de las mismas y nos las envuelven dentro de contextos históricos y religiosos en los que se desarrollaron, de manera indirecta nos muestran también datos de religiosidad y piedad popular. 
En resumen:

\begin{tabular}{|l|l|l|}
\hline \multicolumn{3}{|c|}{ ARCHIVO MONÁSTICO/CONVENTUAL } \\
\hline \multicolumn{1}{|c|}{ Series documentales } & \multicolumn{1}{|c|}{ Contenidos } & \multicolumn{1}{c|}{ Otros archivos } \\
\hline Capellanías y obras pías & $\begin{array}{l}\text { Economía espiritual, } \\
\text { relación de bienes, } \\
\text { religiosidad, arte, etc }\end{array}$ & Parroquiales y diocesanos \\
\hline Escrituras de patronazgo & $\begin{array}{l}\text { Economía espiritual, } \\
\text { beneficios, bienes }\end{array}$ & Parroquiales \\
\hline Noviciado & $\begin{array}{l}\text { Datos biográficos, } \\
\text { educación, religiosidad }\end{array}$ & ---- \\
\hline Libros de becerro & $\begin{array}{l}\text { Datos históricos, } \\
\text { privilegios, beneficios }\end{array}$ & $\begin{array}{l}\text { Monásticos y } \\
\text { conventuales }\end{array}$ \\
\hline
\end{tabular}

\section{Series para la investigación histórica en los archivos beneficiencia}

Son los archivos de las instituciones dedicadas a las labores de caridad y beneficencia como asilos, hospitales, hogares, orfanatos, etc. Para comprender el papel que desempeñaron estas instituciones, especialmente en sus primeras etapas, dado que es de entonces cuando se conserva un mayor volumen documental, nos será muy útil entender el sentido reverencial de la pobreza en la mentalidad cristiana desde la Edad Media, para la cual el pobre era testimonio de la vida de Cristo. De este modo, la asistencia al pobre no se entendía como una obligación, sino que se impregnaba de sentimientos religiosos. El cambio de mentalidad surge en el siglo XIV debido a la aparición de nuevos imperativos económicos y sociales. Entonces se tacha la pobreza de vicio y la vagancia de delito. Se producen las terribles epidemias de peste negra, la proliferación de pobres y vagabundos, niños expósitos, pícaros, etc. Todo ello explica el elevado número de centros asistenciales en España durante los siglos XV y XVI gestionados por la Iglesia católica.

Más tarde, en el siglo XVII, el Estado asume la beneficencia como una parte más de sus competencias ${ }^{13}$. La Ley General de Beneficencia de 1822, el ordenamiento legal de la pobreza y la mendicidad, en los albores del Liberalismo, apuesta por la previsión frente a las medidas coercitivas de resonancias dieciochescas. Poco tiempo después, el Código Penal de 1850 reprime la mendicidad con una pormenorizada tabla sancionadora. En la citada tarea colaboran desde el siglo XIX y hasta la fecha la Iglesia católica, el Estado, los profesionales de la sanidad y gran número de instituciones, en la que se incluye el Instituto de Reformas Sociales ${ }^{14}$.

${ }^{13}$ Cruz Arias, M $\mathrm{M}^{\mathrm{a}}$ J. "Fondos de instituciones benéfico-asistenciales anteriores al siglo XX conservadas en el Archivo de la Diputación de Toledo", Memoria Ecclesiae XI (1997), pp. 261-272.

${ }_{14}$ Maza Zorrilla, E. Pobreza y beneficencia en la España Contemporánea. Barcelona: Ariel, 1999, pp. 161-163. 
En la actualidad, el papel de la Iglesia católica en estas cuestiones no deja de ser importante y prueba de ello son los numerosos frentes sociales con los que la Iglesia trabaja y colabora para ayudar a los más necesitados (comedores, asilos, centros de rehabilitación de drogadictos, ect). La circunstancias son otras pero el trabajo es el mismo. Destacar series documentales representativas del cuadro de clasificación de los archivos de beneficencia es una tarea relativamente sencilla si entendemos que sus principales puntos de inflexión fueron los enfermos y los niños.

1. Por ello, en primer lugar, traemos a colación la serie documental, Asientos de niños, situada dentro de la sección beneficencia: servicios. Es la que nos permitirá conocer expedientes de los huérfanos españoles desde siglos atrás, especialmente destacables los siglos XVI-XVIII. Son contenidos que tienen un alto valor estadístico y que han permitido elaborar mapas estadísticos sobre las épocas en las que la orfandad llegó a ser un importante problema para el Estado español que no podía asumir el coste que su manutención representaba. Todos aquellos que acometan estudios demográficos o sociológicos y que de forma particular afecten a la población infantil deberán recurrir a estos archivos dado que la información contenida en ellos representa una parte importante de los datos que se conservan, especialmente anteriores al siglo XVIII donde son casi exclusivos.

2. Por otro lado destacaremos la serie documental, Asientos de enfermos, que como en el caso anterior también se localiza dentro de la sección beneficencia: servicios, aunque en este caso pertenece a la subsección hospitales. Dentro del cuadro de clasificación sobre estas entidades debe aparecer una amplia sección dedicada a los hospitales y a la sanidad dado que es una de las tareas más importantes llevadas a término por estas instituciones. Muchos son los aspectos que podemos estudiar si nos decantamos por esta serie documental. Conocer las enfermedades o epidemias que afectaron a la sociedad española en siglos determinados, determinar qué enfermedades afectaban a las clases más pobres, saber las técnicas médicas que se aplicaban con los enfermos es posible accediendo a esta documentación. Por ello serán contenidos de gran riqueza para todos los trabajos que aborden la sanidad en la España de los siglos XVI al XVIII. 
En resumen:

\begin{tabular}{|l|l|l|}
\hline \multicolumn{3}{|c|}{ ARCHIVO BENEFICENCIA } \\
\hline \multicolumn{1}{|c|}{ Series documentales } & \multicolumn{1}{|c|}{ Contenidos } & \multicolumn{1}{c|}{ Otros archivos } \\
\hline Asientos niños & $\begin{array}{l}\text { Orfandad, estadísticas, } \\
\text { demografía }\end{array}$ & Órdenes de vida activa \\
\hline Asientos enfermos & $\begin{array}{l}\text { Sanidad, estadísticas, } \\
\text { epidemias, demografía }\end{array}$ & Órdenes de vida activa \\
\hline
\end{tabular}

\section{Series para la investigación histórica en los archivos de órdenes religiosas de vi- da activa}

En líneas generales los archivos de órdenes religiosas de vida activa albergan la documentación de aquellas instituciones que surgen en los tiempos modernos, después de la Reforma Protestante y el Concilio de Trento, muy ligadas a la educación y a la beneficencia. Entre ellas podemos situar a Jesuitas, Capuchinos, Escolapios, Salesianos, Maristas etc, aunque existen otras muchas. Todas ellas proliferan en tiempos cercanos a los nuestros y responden a una mentalidad renovadora dentro de la Iglesia. Los religiosos apenas se distinguen de los clérigos seculares o diocesanos. Todos ellos mantienen vida en común pero en la gran mayoría de casos suprimen el coro, dedicando su tiempo a la vida apostólica o pastoral. Estos institutos se gobiernan bajo la obediencia del superior general que posee jurisdicción sobre todos los miembros. Le sigue jerárquicamente el provincial y en la base de la pirámide un superior local. Este nuevo género de vida religiosa ha dado lugar a una interesante producción documental cuya cronología es más cercana a fechas actuales $^{15}$. Dado la especificación de las mismas, los cuadros de clasificación que se diseñan para estas entidades deben responder fielmente a su perfil de trabajo y constitución. Es decir, se tratará de unos cuadros clasificatorios específicos que darán cabida exclusivamente a las competencias que esa institución tiene. Por todo ello, es más complejo establecer líneas generalistas aplicables a la documentación.

Dejando al margen los contenidos relacionados con la caridad, dado que los archivos de beneficencia son sin lugar a duda los que mejor la representan, para las órdenes de vida activa tomaremos de referencia dos bloques claves: la docencia y la misión, situadas ambas dentro de la sección oficios.

1. Algunas órdenes religiosas de vida activa han dedicado sus esfuerzos a lo largo de los años a tareas relacionadas con la formación de jóvenes generando en estos procesos una abundantísima documentación que abarcará todos los aspectos educativos. Por ello, estos archivos nos ofrecerán dos bloques de

15 Rosselló Lliteras, J. "Panorama archivístico de las congregaciones religiosas dedicadas a la enseñanza”, Memoria Ecclesiae XIII (1966), p. 127. 
contenidos interesantes. Por una parte, los más abundantes son los que se referirán a los pupilos que han recibido formación en estos centros cutos contenidos servirán para localizar alumnos, establecer perfiles educativos y sociológicos, estudiar la población estudiantil: volumen, sexos, edades, etc. Y por otra, contenidos que tienen que ver con la educación en general: aplicación de leyes sobre educación, planes de estudios, formación académica, etc. Algunos de estos archivos han aportado documentalmente datos biográficos de la vida de personajes representativos en el panorama social, cultural, político de nuestro país.

2. Otras órdenes de vida activa desarrollan su trabajo en cuestiones relacionadas con las misiones. La documentación por ellas producida suele ser muy voluminosa y de gran interés para el estudio de otras culturas. Sus contenidos nos permiten abordar cuestiones relacionadas con poblaciones indígenas, trabajos demográficos, sanitarios, educativos, sociológicos, etc. Estos archivos son la base de nutridos trabajos y de importantes informes que permiten a instituciones públicas y privadas actuar en estos países y desarrollar políticas de trabajo muy eficaces que a día de hoy están viendo sus frutos.

En resumen:

\begin{tabular}{|l|l|l|}
\hline \multicolumn{3}{|c|}{ ARCHIVO ÓRDENES DE VIDA ACTIVA } \\
\hline \multicolumn{1}{|c|}{ Series documentales } & \multicolumn{1}{|c|}{ Contenidos } & \multicolumn{1}{c|}{ Otros archivos } \\
\hline Docencia & $\begin{array}{l}\text { Aspectos educativos, } \\
\text { perfiles, sociología }\end{array}$ & Seminarios \\
\hline Misión & $\begin{array}{l}\text { Demografía, sanidad, } \\
\text { educación }\end{array}$ & Beneficencia \\
\hline
\end{tabular}

\section{Series para la investigación histórica en los archivos de seminarios}

Los seminarios, instaurados a partir del Concilio de Trento, son los centros de formación para el clero. En sus archivos, en líneas generales, se custodia documentación referida a estatutos y constituciones, expedientes personales, becas, patrimonio, actas académicas, etc. En los primeros siglos de la Iglesia, los obispos recorrían sus diócesis en busca de jóvenes para adscribirlos a su servicio y, posteriormente al desempeño de las funciones sacras. Sin embargo, la floración heterodoxa obligó a la Iglesia a extremar su vigilancia en lo relativo a la selección de candidatos. Para ello, se crean en el siglo II las escuelas de catequética. Ya en el siglo $\mathrm{V}$ aparecen los antecedentes más remotos de los seminarios. Más tarde, en el siglo VI aparecen las escuelas episcopales. Los siglos IX-XI coinciden con la máxima postración del clero y con el inicio del declive de las escuelas episcopales. Tras la reforma cluniacense florecen las escuelas catedralicias. El III Concilio de Letrán 
dispuso en 1119 que en todas las catedrales existiera la figura del maestrescuela con la misión de enseñar a los clérigos y a estudiantes pobre.

La reforma del clero era una necesidad hondamente sentida por la Iglesia durante los siglos inmediatos a Trento. Como respuesta a este clima se celebraría, como ya hemos visto en marcadas ocasiones, el Concilio de Trento (1545-1563). Sin duda, el cumplimiento de estos preceptos exigía una mejor instrucción del clero. Para alcanzar este propósito surgen en el siglo XVI los seminarios ${ }^{16}$.

1. Dentro de la estructura que configura el cuadro de clasificación para este tipo de archivos nosotros vamos a resaltar aquellas series documentales que están intrínsecamente relacionadas con el profesorado y el alumnado. Estas series aportan contenidos muy importantes para la historia. En primer lugar, nos acercan a la espiritualidad dado que el número de expedientes de alumnos por año puede ser visto como un dato clave en este tema, es decir, los años de más alumnos en los seminarios son entendidos como épocas de mayor esplendor religioso en detrimento de los años en que el número de vocaciones es menor. Por otro lado, nos informan sobre quiénes fueron los alumnos y profesores en dichos seminarios, es decir, nos aportan nutridos datos biográficos que podrán ser utilizados para la confección de biografías. Son una fuente importantísima de contenidos para la educación, especialmente en los siglos XVII-XVIII, puesto que en algunas poblaciones españolas, sirva de ejemplo la ciudad de Badajoz, fueron la única fuente de formación universitaria cuando nuestra universidad aún no había sido concebida. Por ello, sus archivos recogen datos educativos únicos.

2. Además, algunos de estos centros educativos para el clero poseen un patrimonio artístico que merece la pena resaltar. Sus archivos recogen documentación de estas piezas, muchas de ellas sacramentales (cálices, patenas, crucifijos, casullas, manteles bordados, etc), algunas otras artísticas (cuadros y esculturas), otras bibliográficas (libros). Los archivos dan fe de cada una de estas posesiones de una manera detallada aportándonos datos artísticos, bibliográficos y nominativos dado que exponen, en los casos de donaciones, información acerca de los benefactores.

${ }^{16}$ Blanco Cotano, M. El primer centro universitario de Extremadura: Badajoz 1973: Historia pedagógica del Seminario de San Atón. Cáceres: Universidad de Extremadura, 1998, p. 25. 
En resumen:

\begin{tabular}{|l|l|l|}
\hline \multicolumn{2}{|c|}{ ARCHIVO MONÁSTICO/CONVENTUAL } \\
\hline \multicolumn{1}{|c|}{ Series documentales } & \multicolumn{1}{|c|}{ Contenidos } & \multicolumn{1}{c|}{ Otros archivos } \\
\hline Profesorado y alumnado & $\begin{array}{l}\text { Educación, espiritualidad, } \\
\text { biografías }\end{array}$ & Órdenes de vida activa \\
\hline Patrimonio artístico & $\begin{array}{l}\text { Datos artísticos, } \\
\text { biográficos, nominativos, } \\
\text { etc. }\end{array}$ & $\begin{array}{l}\text { Parroquiales, } \\
\text { catedralicios, monásticos } \\
\text { y conventuales }\end{array}$ \\
\hline
\end{tabular}

\section{SISTEMATIZACIÓN DE CONTENIDOS POR TIPOLOGÍAS DE ARCHI- VOS ECLESIÁSTICOS}

Llegados a este punto del estudio y antes de dar por concluido el mismo hemos creído conveniente exponer de manera sistematizada los contenidos resultantes tras el estudio de las diferentes tipologías de archivos con los que la Iglesia católica cuenta en la actualidad. De este modo los interesados podrán acceder fácilmente a los contenidos y saber en qué archivo eclesiástico podrán localizar datos relativos a cada una de estas materias. Este apartado, sin duda alguna, facilitará al investigador el acceso eficaz a los contenidos. Dado las complejas estructuras que la Iglesia católica presenta saber qué documentación se ubica en cada tipo de archivo es una tarea realmente importante que no siempre está al alcance de los interesados. Para ello nosotros hemos diseñado una estructura muy sencilla y básica. En primer lugar, un breve resumen que nos contextualiza la materia a tratar, en segundo término, los contenidos que se sitúan dentro de dicho bloque y por último, los archivos eclesiásticos más representativos que presentan documentos sobre dichos contenidos, es decir, los que nos permiten el mejor estudio de cada una de estas cuestiones.

\section{Cuestiones económicas}

Por cuestiones económicas entendemos aquellos temas que resultan de la gestión de los bienes, materiales o no, con los que las diferentes estructuras que constituyen la Iglesia católica cuentan. Como es lógico, la administración de los bienes eclesiásticos genera una abundante documentación que en cierto modo no presenta un interés importante debido a la similitud con la generada por cualquier entidad civil (facturas, nóminas, recibos, etc). Estas variadas cuestiones darían lugar a un bloque específico de contenidos que podríamos denominar administrativo-contable, en el que tendrían cabida todos y cada uno de los tipos de archivos con los que la Iglesia cuenta dado que todos ellos tienen una parte patrimonial que deben gestionar, como si se tratara de cualquier empresa. Sin embargo, existen ciertos contenidos de tipo económico que 
son merecedores de ser resaltados dado que no aparecen en todas las entidades y además aportan datos de suma relevancia para la historia en estas cuestiones.

\begin{tabular}{|c|c|}
\hline Contenidos & Archivos \\
\hline $\begin{array}{l}\text { - capellanías y obras pías } \\
\text { - libros de tumbos, becerros } \\
\text { o cartularios } \\
\text { - documentación sobre } \\
\text { diezmos y primicias } \\
\text { - censos }\end{array}$ & $\begin{array}{ll}\text { - } & \text { archivos parroquiales } \\
\text { - } & \text { diocesanos } \\
\text { - } & \text { catedralicios } \\
\text { - } & \text { monásticos y conventua- } \\
& \text { les }\end{array}$ \\
\hline
\end{tabular}

\section{Cuestiones sociales}

Este bloque temático es sin duda uno de los más amplios y en cierto modo heterogéneo dado que la Iglesia ha abordado a lo largo de su dilatada historia infinidad de cuestiones de carácter social o que, de un modo u otro, han afectado a la sociedad en general. Si partimos de la premisa de que la Iglesia trabaja por y para la sociedad podremos hacernos idea de la importancia del mismo. Canalizar estas actividades y especialmente la documentación que en ellas se genera es una tarea muy ardua que obliga a los archiveros eclesiásticos a tener unos conocimientos precisos de los organigramas de cada una de las entidades que generan la documentación. Sin lugar a duda, los contenidos más relevantes son los que se relacionan con la caridad, orfandad y sanidad dado que aportan una abundantísima documentación que ha sido generada por la Iglesia católica desde hace varios siglos y que permite el estudio de las cuestiones sociales en épocas donde todavía el Estado no había asumido dichas competencias.

\begin{tabular}{|c|c|}
\hline Contenidos & Archivos \\
\hline $\begin{array}{l}\text { - } \text { asiento de niños y huér- } \\
\text { fanos } \\
\text { - } \text { sanidad: gestión de hospi- } \\
\text { tales, personal, etc. } \\
\text { - enfermedades } \\
\text { - mendicidad } \\
\text { - beneficencia }\end{array}$ & $\begin{array}{l}\text { - } \text { parroquiales } \\
\text { - de beneficencia } \\
\text { - de órdenes religiosas de } \\
\text { vida activa } \\
\text { - de seminarios }\end{array}$ \\
\hline
\end{tabular}

\section{Cuestiones demográficas}

Este bloque temático recogerá aquellos contenidos que tienen que ver con el estudio de la población humana en relación a su estructura, dimensión, evolución y 
características. Los archivos de la Iglesia deben presentar documentación sobre estas cuestiones dado que las entidades eclesiásticas trabajan con las personas desde multitud de vertientes y su estudio se convierte en una cuestión vital en multitud de situaciones y contextos.

\begin{tabular}{|l|l|}
\hline \multicolumn{1}{|c|}{ Contenidos } & \multicolumn{1}{c|}{ Archivos } \\
\hline$\bullet$ padrones parroquiales & $\bullet$ parroquiales \\
- Índices de mendicidad & $\bullet$ diocesanos o episcopales \\
- $\begin{array}{l}\text { índices de gestión sani- } \\
\text { taria }\end{array}$ & $\bullet$ de beneficencia \\
\hline
\end{tabular}

\section{Cuestiones educativas}

Este bloque temático dará cabida a los contenidos que tienen que ver con la educación, no sólo de la formación religiosa eclesiástica, es decir, de la que compete a seminaristas, novicios/as y sacerdotes, sino también de la que incumbe a la sociedad en general dado que durante un dilatado periodo de tiempo, como ya ocurrió con las cuestiones benéfico-asistenciales, la Iglesia católica fue la encargada de la formación de las clases sociales, desde las más pobres continuando con sus labores de caridad, hasta las clases más altas, que veían en el clero un estrato bien formado y eficaz para estos menesteres.

\begin{tabular}{|c|c|}
\hline Contenidos(rama eclesiástica) & Archivos \\
\hline $\begin{array}{l}\text { - } \quad \text { expedientes de alumnos } \\
\text { - } \text { profesores } \\
\text { - } \text { escuelas catedralicias } \\
\text { - noviciados } \\
\text { - } \text { biografías } \\
\text { - } \text { planes de estudios }\end{array}$ & $\begin{array}{ll}\text { - } & \text { catedrales } \\
\text { - } & \text { Conventos y monasterios } \\
\text { - } & \text { órdenes de vida activa, } \\
\text { - } & \text { seminarios. }\end{array}$ \\
\hline
\end{tabular}

\begin{tabular}{|c|c|}
\hline Contenidos(rama civil) & Archivos \\
\hline $\begin{array}{l}\text { - } \quad \text { expedientes de alumnos, } \\
\text { - } \quad \text { profesores } \\
\text { - } \text { planes de estudios } \\
\text { - leyes educativas }\end{array}$ & - órdenes de vida activa \\
\hline
\end{tabular}




\section{Cuestiones del arte}

Por todos es sabido el importantísimo patrimonio artístico con el que la Iglesia católica ha contando a lo largo de toda su existencia. Un patrimonio que alberga todas las ramas: pintura, escultura, arquitectura, orfebrería, etc. Sin embargo, no es esta la cuestión que realmente nos interesa en este estudio sino la documentación que respalda a todas y cada una de esas piezas artísticas y que para la historia es también ciertamente importante. Nunca se hubiera concebido una grandiosa catedral sin unos planos previos que la trazaran, una escultura o pintura sin un boceto, una pieza musical sin una partitura. Toda esa documentación se custodia en los archivos eclesiásticos y por ello decimos que los archivos de la Iglesia cuentan con un importantísimo patrimonio documental para la historia del arte.

\begin{tabular}{|l|ll|}
\hline \multicolumn{1}{|c|}{ Contenidos } & \multicolumn{1}{c|}{ Archivos } \\
\hline - nóminas de artistas & $\bullet$ catedralicios \\
- planos de catedrales, & - parroquiales \\
& iglesias, monasterios, & $\bullet$ monasterios y conventos \\
etc. & - seminarios \\
- bocetos de pinturas & & \\
- reliquias & & \\
- jocetos de esculturas & & \\
\hline
\end{tabular}

\section{Cuestiones histórico-culturales}

Ubicamos este apartado en último lugar no por su menor importancia sino por la amplitud a la que da cabida el mismo dado que las cuestiones histórico-culturales en el marco en el que nos desenvolvemos son muchas y variadas.

\begin{tabular}{|l|l|}
\hline \multicolumn{1}{|c|}{ Contenidos } & \multicolumn{1}{c|}{ Archivos } \\
\hline - docencia & $\bullet$ parroquiales, \\
- expedientes de músicos & $\bullet$ catedralicios, \\
- planos & $\bullet$ monástico-conventuales. \\
- mapas & \\
- monedas & \\
- medallas & \\
\hline
\end{tabular}




\section{CONCLUSIONES GENERALES}

Damos por concluido este trabajo dedicado al análisis de los contenidos más representativos incluidos en cada uno de los archivos que constituyen la Iglesia católica, no sin antes recordar que son los conservadores de una importantísima parte de la cultura de todos los tiempos y remarcar la necesidad inminente de que en todos los archivos que componen la Iglesia se efectúen sin más dilación tareas de ordenación y clasificación de fondos que, no sólo pongan a la luz documentación hasta la fecha inédita, sino que eviten su destrucción, es decir, la lapidación de la historia eclesiástica.

En líneas generales podemos manifestar que los contenidos que se sitúan en los archivos eclesiásticos serán de gran utilidad para la realización de variados trabajos de investigación, tesinas, tesis, etc. Especialmente y de forma general para no caer en repeticiones, los archivos de la Iglesia albergan una documentación de suma importancia para la historia del arte dado que en todos sus archivos se conservaba algún documento que de fe del trazado de una obra artística y que nos permita su estudio y conservación futura. Por ello, los historiadores del arte verán gratamente colmados sus intereses estudiando la documentación de estos archivos, especialmente catedralicios y monásticos. Además, son de singular interés para la el estudio de la beneficencia, especialmente en épocas en las que el Estado no había asumido al pobre como parte de sus competencias.

De ello deducimos que durante una parte concreta de nuestra historia las cuestiones benéficas se podrán estudiar exclusivamente accediendo a los archivos eclesiásticos, especialmente los de beneficencia, órdenes religiosas de vida activa y parroquiales. Por otro lado, los archivos eclesiásticos son de gran interés para el estudio de la cultura y de la educación dado que durante parte de su historia han desempeñado gratamente estas tareas. De entre todos los existentes para estas cuestiones accederemos a los archivos de seminarios, conventos y monasterios que fueron durante muchos siglos depósito activo de la cultura. 